\title{
A Cross-cultural Comparison of Chinese and American Tourists' Satisfaction with Chengdu
}

\author{
Xueqian Liu ${ }^{1, *}$ \\ ${ }^{1}$ International College, University of The Thai Chamber of Commerce, Bangkok, Thailand
}

\begin{abstract}
Compared with China's domestic and outbound tourism, China's inbound tourism has developed relatively slowly. An understanding of cultural similarities and differences can support destination managers in formulating strategies and increase the satisfaction of inbound tourists. As one of the best tourist cities in China, Chengdu is an important destination for inbound tourists. Meanwhile, American tourists are the major source of tourists for Chengdu's inbound tourism. Based on the Cultural Dimensions Theory proposed by Hofstede, this research focuses on a cross-cultural comparison of two important markets for Chengdu tourism: Chinese and American tourists. In addition, electronic word-of-mouth (E-WOM) has become an important source of tourist information, the analysis of E-WOM may provide more insights into users' feelings than questionnaires. This study uses content analysis to quantify online reviews and importance performance analysis to compare the importance and satisfaction of Chinese and American tourists with destination attributes. The results clearly show the comparison between the two groups in destination assessment.
\end{abstract}

\section{Introduction}

Social media is considered an essential source of travel information in the era of web 2.0, because it affects how people search and share information [1]. It is changing the way tourists search, share and process related travel information, enabling travelers to share their travel experiences through social media at different time [2]. Contents and comments posted by users on social media can be viewed as electronic word of mouth (E-WOM) [3]. E-WOM tends to reflect what tourists really think of destinations.

As one of the best tourist cities in China, Chengdu has abundant tourism resources. However, due to its inland location, Chengdu is not quite internationally influential. The quantity and quality of tourism resources have great potential for development, and there is also a lot of room for exploring the inbound tourism market. The United States is the main source of inbound tourists to Chengdu, and the number of American tourists is increasing year by year. However, there is little research on American tourists in Chengdu, on satisfaction comparison.

Importance Performance Analysis (IPA) is a tool used to analyze customer satisfaction with products or services, and formulate corresponding marketing strategies based on customer needs [4]. Importance Performance Analysis (IPA) allows researchers to visually identify the gap between tourists' perceptions of the importance of a destination attribute and the actual performance of that attribute [5]. Therefore, IPA can not only analyze tourist satisfaction, but also help destination managers to make corresponding plans. Content analysis is a research method that provides systematic and objective means to describe and quantify oral, visual or written data [6]. Different from interview, questionnaire survey and other methods, it is a non-invasive method. Its advantage is that it does not affect social behavior.

Although previous studies have used various methods such as surveys, case studies and factor analysis to explore customer satisfaction, studies on analyzing tourist satisfaction from the perspective of E-WOM are limited. Therefore, it is important to investigate the key factors that have received more attention from customers in these reviews.

\section{Literature review}

\subsection{Electronic Word-of-mouth and tourism}

A widely used definition of E-WOM is "any positive or negative statement made by potential, actual or former customers about a product or company that is made available to a multitude of people and institutions via the internet" [7].

In the travel industry, online reviews include the experience of visitors with products and services; online reviews with these characteristics can be considered as online word of mouth [8]. Travelers write online reviews to help other travelers by sharing their experience with products, services and their satisfaction. After consumption, customers give feedback online, and such online reviews are fast, timely, and available everywhere, and have become increasingly important [9]. The way travelers choose and evaluate travel services has

*Corresponding author: 1xq94312@gmail.com 
fundamentally changed due to the rapid and widespread appearance of user-generated content [10].

\subsection{Destination satisfaction}

Destination satisfaction refers to the evaluation of tourists on their emotional response to the products and service utilized in the tourist destination [11]. Tourist satisfaction is an important factor for the success of destination marketing, which affects choice of destination, consumption of tourism products/services and intention to revisit [12]. By measuring the satisfaction of tourists, we can determine whether a tourist destination meets the needs of tourists, which is helpful for tourism decision makers to improve the quality of tourism products and services and attract more tourists [13]. It has been established in tourism literature that the overall satisfaction of tourists can be explored by analyzing tourists' evaluation of different attributes of destinations [14-15]. Therefore, it is necessary to examine the attributes that affect destination satisfaction and make recommendations to tourism policy makers.

\subsection{Cross-cultural studies}

Culture is collective thinking that can usually distinguish different groups and various members [16]. When people have the same cultural background, they have a clear understanding of themselves and others. Tourists' way of thinking and their social environment will make their value judgments different [17]. As indicated in the previous literature, cross-cultural group's travel style differences can only be explained by the traveler's personal preferences or characteristics. These behaviors are likely to be rooted in their culture. Therefore, the cross-cultural comparison of tourists from different countries is essential for understanding the perceptions and behaviors of different tourists.

According to Hofstede Insights, China and America are significantly different in four of the six cultural dimensions [16]. Firstly, China has a larger power distance and is considered to accept unequal power distribution, while the United States is less likely to accept power inequality. Secondly, China is characterized by collectivism where people act in the interests of the group and not necessarily of themselves, while the United States emphasizes individualism where they care more about their own interests. Meanwhile, China has a stronger longterm orientation, which means that the Chinese people are diligent and thrifty for the long-term prosperity of the society and individuals. Finally, China is less indulgent than the United States which means China is a restrained society where people do not place too much emphasis on leisure time and control the satisfaction of its desires. In this empirical study, it is expected that these differences will be reflected in the traveler's satisfaction and perception of the importance of destination attributes.

\section{Method}

\subsection{Data collection}

The review data of tourists on Dianping and TripAdvisor in 2019 was selected as the sample for this study. The data were collected manually from websites. According to the characteristics of reviews, the rules for sample selection are as follows: only one review of the same content with the same ID was taken; the extreme and exaggerated reviews were removed; the reviews promoted by the merchants were removed; the reviews that were not from tourist were removed; the comments that did not mention factors affecting tourist satisfaction were removed. After reviewing more than 400 reviews for each subcategory, similar indicators tended to make sense. After meeting the inclusion criteria for this study, a total of 800 reviews were selected for each subcategory: 400 reviews on TripAdvisor and 400 reviews on Dianping. In total, 2400 reviews were analyzed for destination satisfaction.

\subsection{Coding}

Online reviews were analyzed using a coding scheme designed for this study. The first step is to build a coding scheme. According to the research of previous scholars, the indicators that tourists may pay attention to during the travel process and the services they may use are summarized to form a coding scheme (shown in Table 1). In the second step, two independent coders code all collected online reviews based on the indicators of the coding scheme and then count the frequency of the corresponding indicators. In the third step, the coder scores the opinions in the reviews through words that reflect the positive or negative emotions of tourists such as "good", "bad", "crowded", etc. $(1=$ terrible, $2=$ poor, $3=$ neutral, $4=$ good, and $5=$ excellent). When the coder judges that the expression of the opinion is positive, it scores 4 ; when the opinion is negative, it scores 2 . When the coder judges that there is a strong positive opinion, a score of 5; when a strong negative opinion appears, a score of 1; when the coder cannot judge the polarity, a score of 3 .

Table1. Tourist Review Coding Scheme

\begin{tabular}{|c|l|}
\hline Category & Indicator \\
\hline Urban atmosphere & 1. The rhythm of life \\
\hline Tourist attraction & $\begin{array}{l}\text { 5. Overall attraction evaluation 6. } \\
\text { Local features of scenic spot, 7. } \\
\text { Infrastructure of Scenic spot, 10. } \\
\text { Scenic spot management, 11. } \\
\text { Environment of the scenic spot }\end{array}$ \\
\hline Transportation & 13. Taxi, 16. Railway station \\
\hline Accommodation & $\begin{array}{l}\text { 17.Overall accommodation } \\
\text { evaluation 18. Hotel facilities, 19. } \\
\text { Hotel price, 20. Hotel catering, 21. } \\
\text { Hotel location, 22. Hotel } \\
\text { environment, 23. Hotel room, 24. } \\
\text { Hotel service attitude, }\end{array}$ \\
\hline
\end{tabular}




\begin{tabular}{|l|l|}
\hline Catering & $\begin{array}{l}\text { 26. Overall catering evaluation 27. } \\
\text { Catering diversity, 29. Catering } \\
\text { Services, 30. Catering price, 31. } \\
\text { Catering quality, 32. Catering } \\
\text { environment }\end{array}$ \\
\hline
\end{tabular}

\begin{tabular}{|c|l|}
\hline Shopping & $\begin{array}{l}\text { 34. Diversity of shopping places, } 35 . \\
\text { Diversity of commodities }\end{array}$ \\
\hline
\end{tabular}

Chinese

Table2. Top 40 High-frequency Words

\begin{tabular}{lclc|llll}
\hline Keywords & Frequency & Keywords & Frequency & Keywords & Frequency & Keywords & Frequency \\
\hline Chengdu & 828 & Next Time & 118 & Chengdu & 776 & Friendly & 204 \\
Service & 516 & Normal & 109 & Hotel & 712 & Tea & 196 \\
Delicious & 510 & Snacks & 103 & Food & 654 & City & 196 \\
Hotel & 393 & Chunxi Road & 101 & Great & 632 & Recommend & 184 \\
Good & 374 & Front Desk & 101 & Pandas & 540 & Chinese & 160 \\
Special & 352 & Convenient & 98 & Staff & 532 & Buffet & 160 \\
Taste & 333 & Restaurant & 98 & Room & 508 & Beautiful & 156 \\
Recommend & 275 & Worthwhile & 96 & Good & 380 & English & 156 \\
Environment & 257 & Park & 96 & Service & 364 & Location & 156 \\
Like & 249 & Mount Qingcheng & 94 & Well & 304 & Street & 140 \\
Tofu & 172 & Scenic Spot & 79 & Like & 288 & Delicious & 124 \\
Line up & 159 & Wuhou Temple & 76 & Best & 280 & Helpful & 124 \\
Enthusiastic & 151 & Du Fu Cottage & 72 & Nice & 272 & Temple & 108 \\
Friends & 150 & Life & 71 & People & 240 & Subway & 100 \\
Feature & 149 & Spicy & 70 & Restaurant & 264 & Special & 92 \\
Room & 148 & Take Photo & 67 & Excellent & 224 & History & 88 \\
Alley & 145 & Transportation & 65 & Experience & 220 & Variety & 88 \\
Beef & 131 & Subway & 60 & Wonderful & 220 & Alley & 78 \\
Location & 121 & Hotpot & 60 & Breakfast & 216 & Comfortable & 75 \\
Pandas & 121 & Price & 60 & Local & 208 & Park & 70 \\
\hline
\end{tabular}

\subsection{Data analysis}

In the IPA grid, the vertical (importance) axis and the horizontal (performance) axis were determined by calculating the average value of each factor. After the average performance factor (X-axis) and the importance factor (Y-axis) of each indicator were calculated, these factors were presented in one of the four quadrants.

The factors in the four quadrants indicate different meanings. The first quadrant is named "Concentrate here," indicating that the customer is concerned about the factor but not satisfied with its performance. The second quadrant is called "Keep up the good work," which means that customers value and are satisfied with the performance of the factor. The third quadrant is called "low priority," which means that customers are not concerned about this factor and are not satisfied with its performance. "Possible overkill" is the last quadrant, which means that customers do not take the factor seriously, but are happy with its performance [4]. \#

\section{Results}

\subsection{Analysis of high-frequency words}

The researcher collected tourist reviews from Dianping and TripAdvisor respectively. After screening, 1,200 valid reviews were obtained from each website. The "Online reviews of Chengdu.txt" was then imported into the
ROST content mining software to filter unrelated words and extract high-frequency feature words. Finally, 40 keywords with the highest frequencies were selected from 1,200 Chinese tourist samples and 1,200 American tourist samples (shown in Table 2).

\subsection{Importance-performance analysis grid}

In order to further analyze the various indicators in the category, researchers imported the importance and satisfaction data of indicators into SPSS 21 software to construct an IPA matrix for each group (shown in Figure 1 and Figure 2). Four quadrants were constructed according to the average of 24 importance attributes and 24 performance attributes. Since the overall evaluation of the category could not locate specific indicators, it would not be displayed in the quadrant. These two grids show some differences between Chinese tourists and American tourists. 


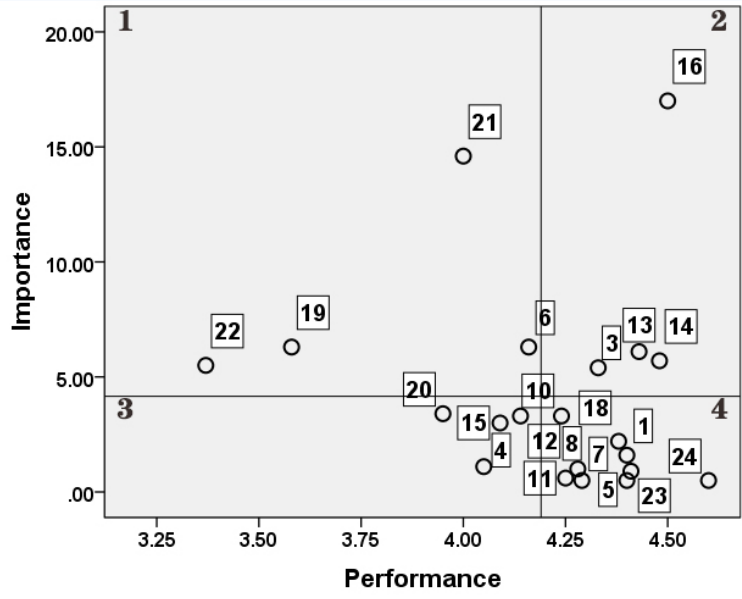

Fig 1. Importance-performance analysis for Chengdu

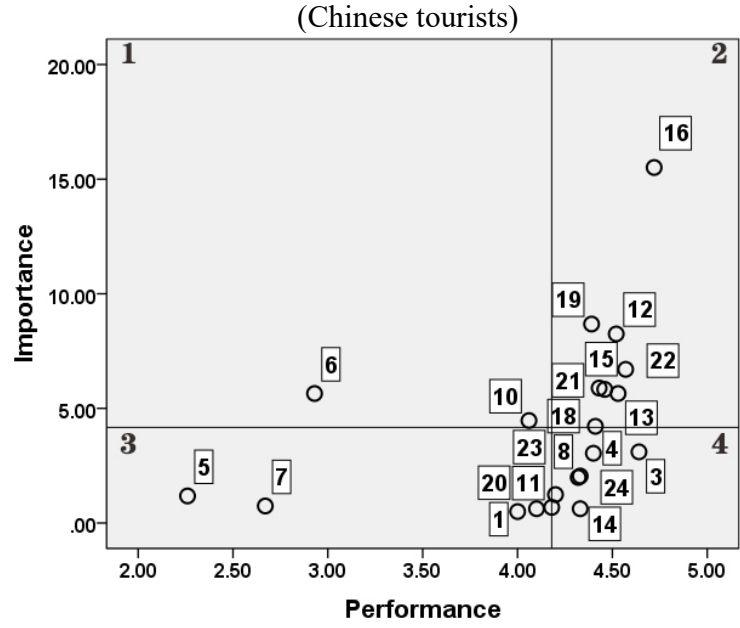

Fig 2. Importance-performance analysis for Chengdu (American tourists)

\section{Conclusions}

The empirical study of this study indicates that the differences between Chinese and American tourists to Chengdu are greater than their similarities, and Chengdu is one of the most popular destinations in China for tourists of both ethnic groups. This comparison indicates that the two ethnic groups have different ways of understanding different aspects of the evaluation object.

The study results show that Chinese tourists are more hesitant to give negative reviews than American tourists. American tourists are more sensitive to crowds than Chinese tourists. As a result, American tourists tend to rate crowded conditions poorly. In terms of catering, Chinese tourists are more concerned about food quality while American ones care more about the service and the environment. American tourists tend to choose upscale restaurants, so they are satisfied with the performance of restaurants in all aspects. Both Chinese and American tourists speak highly of hotels, especially service is an important factor affecting customer satisfaction. When visiting scenic spots, Chinese tourists pay more attention to history and culture than American. These conclusions are consistent with the results of IndividualismCollectivism dimension, power distance dimension and Long term-short term dimension in Cultural Dimensions Theory.
In addition, the indicators located in the four quadrants of the important performance matrix can provide reference for destination managers to formulate relevant strategies. According to the analysis results, the following suggestions are drawn. First of all, destination managers need to promote local culture and cuisine. Second, the management of scenic spots and traffic needs to be improved. Third, the improvement of catering services can attract foreign tourists more.

There are two limitations of this study. First of all, Our data were collected manually, the amount of data obtained is limited. Future Data collection can be combined with computer technology to obtain large amounts of data. Another limitation is that this study analyzes the satisfaction of Chinese and American tourists with only one city. Future research may test the generalizability of the findings by analyzing multiple cities and comparing the results.

\section{References}

1. Xiang, Z., \& Gretzel, U., Tourism Manage, 31, 179188. (2010).

2. Munar, A. M., \& Jacobsen, J. K. S., Tourism Manage, 43, 46-54. (2014).

3. Hanim, K., Sanliöz, Ö., \& Metin, K., Worldw. Hosp. Tour. Themes, 7, 229 - 241. (2015).

4. Martilla, J. A., \& James, J. C., J. Mark, 41, 77-79. (1977).

5. Boley, B. B., McGehee, N. G., \& Tom Hammett, A. L., Tourism Manage, 58, 66-77. (2017).

6. Downe-Wamboldt, B., Health Care Women Int, 13, 313-321. (1992).

7. Hennig-Thurau, T., Gwinner, K. P., Walsh, G., \& Gremler, D. D., J. Interact. Mark, 18, 38-52. (2004).

8. Filieri, R., \& McLeay, F., J Travel Res, 53, 44-57. (2014).

9. Schuckert, M., Liu, X., \& Law, R., J. Travel Tour. Mark, 32, 608-621. (2015).

10. Guo, Y., Barnes, S. J., \& Jia, Q., Tourism Manage, 59, 467-483. (2017).

11. Gannon, M. J., Baxter, I. W. F., Collinson, E., Curran, R., Farrington, T., Glasgow, S., ... Yalinay, O., Serv. Ind. J, 37, 448-465. (2017).

12. Yoon, Y., \& Uysal, M., Tourism Manage, 26, 45-56. (2005).

13. Meng, F., Tepanon, Y., \& Uysal, M., J. Vacat. Mark, 14, 41-56. (2008).

14. Chung, J. Y., \& Petrick, J. F., Asia Pacific J. Tour. Res, 18, 409-420. (2013).

15. Kozak, M., Tour. Anal, 7, 229-240. (2003).

16. Hofstede Insights. Retrieved July 6, 2020, from https://www.hofstede-insights.com/countrycomparison/china,the-usa/ (2017).

17. Lee, G., \& Lee, C. K., Tourism Manage, 30, 922-931. (2009). 